\title{
The Mediating Role of Global and Contingent Self-Esteem in the Association Between Emerging Adults' Perceptions of Family Cohesion and Test Anxiety
}

\author{
Lilla Németh ${ }^{1,2}$ (1) László Bernáth $^{2}$ (] \\ Accepted: 29 January 2022 / Published online: 22 February 2022 \\ (c) The Author(s) 2022
}

\begin{abstract}
The aim of this study is to investigate the importance of family cohesion and self-esteem regarding test anxiety among emerging adults. The study's hypothesis is that cohesion experienced in a university student's family of origin predicts test anxiety. The mediating role of self-esteem was tested considering both global self-esteem and contingent self-esteem based on one's perceived competence. The study also examines whether these associations differ across groups based on gender or residential status. The research questions were investigated using students' self-reported measures of test anxiety, global self-esteem, contingent self-esteem, and family cohesion. The results, based on data gathered from 487 university students, revealed that global self-esteem was a negative predictor of test anxiety and contingent self-esteem was a positive predictor of test anxiety. These findings indicate that the level and source of self-esteem must be considered regarding test anxiety. Further, adaptive family cohesion impacted test anxiety by increasing global self-esteem and decreasing contingent self-esteem. Although these indirect associations were rather weak, they highlight the impact of the family of origin during emerging adulthood. The pattern of interrelations was similar among men and women, as well as among those living together or apart from their family of origin.
\end{abstract}

Keywords Test anxiety $\cdot$ Global self-esteem $\cdot$ Contingent self-esteem $\cdot$ Family cohesion $\cdot$ Emerging adulthood

\section{Introduction}

Test anxiety is defined as fear experienced in academic and evaluative situations (Embse et al., 2018), and it is usually characterized by concerns about one's abilities and the possible negative consequences of evaluation (Cassady \& Johnson, 2002; Embse et al., 2018). A significant body of research has focused on this type of anxiety, and researchers have aimed to identify the antecedents and contributing factors of text anxiety, such as characteristics of the family environment (e.g., Peleg \& Klingman, 2002). However, most existing studies have investigated associations between students' test anxiety and family factors during adolescence

Lilla Németh

nemeth.lilla@ppk.elte.hu

1 Doctoral School of Psychology, ELTE Eötvös Loránd University, 46 Izabella Street, Budapest 1064, Hungary

2 Institute of Psychology, ELTE Eötvös Loránd University, Budapest, Hungary (e.g., Peleg, 2004; Peleg \& Klingman, 2002). Less is known about whether the influence of family processes on test anxiety persists during emerging adulthood. Prior research has demonstrated that university students are strongly affected by test anxiety (Naveh-Benjamin et al., 1997), which can have serious negative consequences for their mental health (e.g., Embse et al., 2018) and academic performance (e.g., Cassady \& Johnson, 2002).

Emerging adulthood is an important transitional period that is distinct from both adolescence and young adulthood. This developmental period is characterized by a great diversity of subjective experiences, demographic circumstances, and identity development (Arnett, 2000). During the transition from adolescence to adulthood (which often includes differentiation from one's family of origin), it is important to understand how family factors influence university students' academic and emotional adjustment, including proneness to test anxiety. Previous studies have identified relationships between family function and emerging adults' life satisfaction, self-compassion, and anxiety (Cheung et al., 2019; Neff $\&$ McGehee, 2010). Cohesion is a comprehensive indicator 
of the family system and relationships (Olson et al., 1979) that has been connected to university students' well-being and emotional distress (Fosco et al., 2012). Little research has examined the relationship between test anxiety and family cohesion, and the existing research on indicators of family structure, relations, and emotional closeness have yielded somewhat inconsistent results (Peleg, 2002, 2004; Peleg \& Klingman, 2002) and have been primarily based on the studies of adolescents.

The aim of this study is to clarify whether test anxiety among emerging adults is influenced by family cohesion and to further investigate the underlying mechanisms of this influence by including self-esteem as a potential mediator. Researchers have demonstrated that self-esteem is affected by the family environment and cohesion (e.g., White et al., 2014), and it is considered an important factor that may predispose individuals to test anxiety (e.g., Dan et al., 2014). Self-esteem is an intrapersonal variable that has been reversely correlated with test anxiety across several studies, according to a meta-analytic review by Embse et al., (2018). The existing study findings indicate that evaluative situations such as examinations may be less threatening for individuals with high self-esteem.

Based on the self-worth theory (Covington, 2000) and control-value theory (Pekrun, 2006) of achievement emotions, it might be reasonable to assume that susceptibility to test anxiety is influenced not only by one's overall level of self-esteem but also the extent to which one's self-esteem is dependent on meeting certain standards or receiving others' approval (contingent self-esteem; Deci \& Ryan, 1995; Johnson \& Blom, 2007). According to the self-worth theory of achievement emotions, academic motivation can also be interpreted as a striving to demonstrate competence and sustain self-worth. Individuals whose self-esteem fluctuates depending on success and failure are more likely than others to demonstrate such self-validation goals (Crocker et al., 2006). These students may perceive evaluative situations to be of heightened importance due to possible consequences for their self-esteem. Control-value theory (Pekrun, 2006) proposes that the perceived value of a certain achievement can increase the level of anxiety experienced during examinations. Therefore, individuals who have highly contingent self-worth may experience higher test anxiety than their peers, because they feel their self-esteem is at stake when their performance is being assessed. Nevertheless, little empirical evidence is available regarding whether test anxiety is associated with contingent self-esteem.

The present study examines the relationship between family cohesion and university students' test anxiety, as well as whether this association is mediated by students' level or contingency of self-esteem. The study also explores whether these interrelations are consistent across groups based on gender or residential status. Previous study findings have indicated that male university students report less support (Allen \& Stoltenberg, 1995) and perceive themselves as more independent from their families of origin (Lopez et al., 1988) than their female peers. Other researchers have found that living together results in more parent-child interactions than living apart (Ward \& Spitze, 2007; White \& Rogers, 1997). Therefore, it is expected that cohesion in the family of origin will be of higher significance among female participants and those living together with their parents than among males and those living independently.

\section{Self-Esteem and Test Anxiety}

The link between test anxiety and global self-esteem (i.e., a person's general evaluation of the self; Rosenberg, 1965) is well established in the literature. The two most significant comprehensive studies in the field of test anxiety research conclude that self-esteem and test anxiety are inversely and moderately associated (Embse et al., 2018; Hembree, 1988), which suggests that evaluative situations may be more threatening for those with low self-esteem than for their peers. Similar results were found across age groups regarding the direction and strength of associations in comparisons of high school and university students (Dan et al., 2014) and among students in late adolescence (Sar1 et al., 2018).

In addition to global self-esteem, contingent self-esteem may also warrant investigation in the context of test anxiety. Contingent self-esteem refers to feelings and evaluations about oneself that are dependent on matching some internal or external standard (Deci \& Ryan, 1995) or one's disposition to earn self-worth through competence and relationships (Johnson \& Blom, 2007). Contingent self-esteem contrasts with true self-esteem, which is a "more stable, more securely based and solid" type of self-worth (Deci \& Ryan, 1995, p. 32). Individuals who are characterized by contingent or true self-esteem may report high scores on a measure of global self-esteem, but the sources of their self-esteem differ (Deci \& Ryan, 1995). Those with low true self-esteem and high contingent self-esteem often demonstrate lower adaptive functioning (e.g., perfectionism, self-criticism, somatic symptoms) than their peers (Johnson \& Blom, 2007).

Contingent self-esteem can be considered within the framework of the self-worth theory of achievement motivation (Covington, 2000) or the control-value theory of achievement emotions (Pekrun, 2006) to examine its potential consequences for academic emotions in general and specifically for test anxiety. According to the self-worth theory of academic emotions, academic motivation can be interpreted as striving to prove one's competence and sustain self-worth. This type of motivation is referred to as "self-validation goals" and is typical among individuals whose selfesteem is highly dependent on success and failure (Crocker et al., 2006). Individuals with high contingent self-esteem 
may worry more than their peers about tests, because their self-esteem is at stake when their achievement is evaluated. Similarly, the control-value theory (Pekrun, 2006) suggests that the extent of anxiety experienced during a test is a function of the test's perceived importance (value) and the individual's perceived control over the situation. Highly contingent self-esteem may be a factor that increases the importance of test performance and thereby increases test anxiety.

However, little empirical evidence is available regarding this relationship. No significant association was found between test anxiety and contingent self-esteem in a study of young adolescents (Cerkez \& Efendic-Spahic, 2016). However, test anxiety was found to be positively correlated with academic contingent self-worth (Lawrence \& Smith, 2017) and various domain-related contingencies of selfworth (Lawrence \& Williams, 2013) in studies of university students.

To summarize, the association between test anxiety and the disposition of contingent self-esteem seems to be theoretically supported. However, additional empirical evidence is needed to confirm this relationship, particularly in regard to the joint impact of global and contingent self-esteem on test anxiety.

\section{Family Cohesion, Self-Esteem, and Test Anxiety}

Family cohesion is one dimension of the Circumplex Model of family functioning (Olson et al., 1979), which is an indicator of the emotional bonding among family members and the extent to which individuals experience autonomy within the family. According to the Circumplex Model, balanced (moderate) levels of cohesion are optimal for individual and family functioning, whereas extremely high cohesion (enmeshment) or extremely low cohesion (disengagement) are dysfunctional (Olson et al., 1979).

Fear of negative consequences of evaluation (e.g., social derogation, worry about failure, and self-doubt) is an important attribute of test anxiety (Cassady \& Johnson, 2002). These fears may be associated with the level of cohesion experienced in the student's family of origin. In a family environment characterized by emotional warmth, students expect few negative reactions and high emotional support from their parents in the case of poor academic performance. Therefore, students who have cohesive families may perceive a possible failure as less of a threat than their peers. Additionally, autonomy is encouraged in families with balanced cohesion, unlike in enmeshed families. As a result, students in cohesive families may be less likely than their peers to overly depend on parents' reactions (which may lead to less fear of social derogation) or to experience self-doubt.
Prior studies have demonstrated associations between family cohesion and development, mental health (White et al., 2014), and anxiety disorders (Ginsburg et al., 1995) among children and adolescents. Other investigations have highlighted the significance of family cohesion among emerging adults regarding academic adjustment (Givertz \& Segrin, 2014), and emotional distress, including anxiety (Fosco et al., 2012).

However, limited empirical data are available on the specific impact of family cohesion on test anxiety. Some research has investigated the role of cohesion specifically in test anxiety; however, most studies of the associations between test anxiety and the family system have examined the importance of other similar attributes. Differentiation, a concept closely related to family cohesion, has been found to be negatively correlated with test anxiety among adolescents (Peleg, 2004) and social anxiety among university students (Peleg \& Zoabi, 2014). Other research has found that social anxiety is closely associated with test anxiety (McDonald, 2001). In one study, adolescents who experienced a heightened sense of belonging and support in the family reported lower test anxiety than their peers (Peleg \& Klingman, 2002); however, no significant links between test anxiety and cohesion were identified among sixth-grade students in another investigation (Peleg, 2002).

The existing empirical knowledge about the family cohesion-test anxiety association is limited, particularly among emerging adults, and the results of former studies are inconclusive. There is a need for further empirical investigation to clarify the link between family functioning (e.g., cohesion) and students' test anxiety. One possible explanation of the ambiguity of former results is that the association in question may be indirect. Abe (2004) found that the link between family cohesion and emotional distress among university students was mediated by self-esteem. Self-esteem should be considered as a mediating factor for the test anxiety-family cohesion relationship because it can be considered as an important intrapersonal predisposing factor of test anxiety (see above), and the association of self-esteem and family cohesion is well established. Several studies have concluded that adolescents (Jaggers et al., 2015; White et al., 2014) and university students (Gorbett \& Kruczek, 2008; Guassi Moreira \& Telzer, 2015) who have cohesive families have higher global self-esteem than their peers. Less is known about the link between family cohesion and contingent selfesteem. However, families with reasonable levels of cohesion, usually characterized by emotional bonding, support, and warmth (Hong et al., 2015; Olson et al., 1979), may provide an environment that supports the development of true self-esteem (in contrast to contingent self-esteem), whereas high contingent self-esteem may be a result of conditional love and regard (Johnson \& Blom, 2007). Therefore, family cohesion is assumed to be inversely associated with 
contingent self-esteem. Prior research findings regarding perfectionism, a construct that is developmentally similar to contingent self-esteem, support this assumption (Segrin et al., 2019).

In conclusion, the existing body of research supports the claim that individuals who experience high relatedness in their families develop higher levels of self-esteem than their peers. However, it is unclear whether a student's level of self-esteem mediates the cohesion-test anxiety relationship and whether similar associations (presumably in a reversed direction) exist in the case of contingent self-esteem.

\section{The Moderating Role of Gender and Residential Status}

Two demographic variables-gender and residential status-were selected for investigation. A secondary aim of the present study is to examine whether these variables influence the strength of the associations between family cohesion and the intrapersonal variables in our model.

Prior studies have yielded consistent results regarding gender differences in that women report higher levels of test anxiety than men (Embse et al., 2018). Additionally, young adult men perceive themselves as more independent from their family of origin (Lopez et al., 1988) and report less family social support and cohesiveness than their female counterparts (Allen \& Stoltenberg, 1995). The significance of family characteristics for test anxiety is likely to differ between males and females; therefore, the present study examines the moderating effect of gender on the relationship between family cohesion and text anxiety.

Residential status reflects the demographic diversity of emerging adults (Arnett, 2000): some individuals live with their family of origin, whereas others have left their parental home temporarily or permanently by this time. Scant research is available regarding the psychological factors associated with parent-child co-residence during emerging adulthood (Mazurik et al., 2020). Most studies have focused on the influence of parent-child co-residence on mental health and well-being (Kins et al., 2009). However, the associations identified were not clear and direct but instead were moderated by other factors, such as the motivational background of co-residence (Kins et al., 2009), which varies depending on the social and cultural context, as does attitudes toward the living arrangement (Newman, 2013). Similarly, consequences of co-residence for the quality of the parent-child relationship have been found to be moderated by other variables, such as the previous quality of the relationship (Ward \& Spitze, 2007; White \& Rogers, 1997). Researchers have consistently found that co-residence results in more parent-child interactions and therefore higher intensity in the relationship, which may amplify supportive aspects of the relationship as well as conflict and tension (Ward \& Spitze, 2007; White \& Rogers,
1997). The present study investigates whether the influence of family cohesion on individual outcomes is stronger for students who live with their family of origin than for those who have left their parental home.

\section{Present Study}

Previous research studies have highlighted the significance of family characteristics (e.g., cohesion) during emerging adulthood and the influence of family factors for adolescents' test anxiety. However, little is known about the association between emerging adults' experiences of cohesion in their family of origin and proneness to test anxiety or about the intrapersonal variables that could potentially mediate this relationship. Prior studies have found that low global self-esteem is a significant predictor of test anxiety, but the relationship of contingent self-esteem and test anxiety has not been clearly defined. Additionally, it has been well established that family influences individuals' self-esteem; however, it is unclear whether global or contingent self-esteem may mediate the relationship between family cohesion and test anxiety. The present study is the first to incorporate all these constructs into a single model to clarify the interrelations between family cohesion, global and contingent self-esteem, and test anxiety. The study also investigates the moderating role of two demographic variables - gender and residential status (i.e., living with or apart from one's family of origin) in these relationships.

The present study tests the following hypotheses:

1. (a) Global self-esteem is negatively related to text anxiety, and (b) Contingent self-esteem is positively related to test anxiety.

2. The associations between adaptive family cohesion and test anxiety are mediated by global and contingent selfesteem in that the former is positively predicted (a) and the latter is negatively predicted (b) by adaptive family cohesion.

3. The strength of the relationships between family cohesion and both aspects of self-esteem, as well as test anxiety, differ by gender in that these associations are stronger for females than for males.

4. The strength of the relationships between family cohesion and both aspects of self-esteem, as well as test anxiety, differ by residential status in that these associations are stronger for those who live with their family of origin than for those who live separately. 


\section{Method}

\section{Participants and Procedure}

A sample of 487 students aged $18-25$ years $(M=20.90$, $S D=1.41$ ) was recruited from a large university in Hungary to take part in the study. Of the participants, 352 were female, 130 were male, and 5 did not specify their gender. Data regarding ethnicity were not collected due to a prohibition on collecting these data under Hungarian law; however, most subjects are presumably of European descent, given the ethnic composition of the university.

Half of participants $(50.1 \%)$ studied educational sciences (i.e., teacher education, pedagogy, or andragogy), $18.3 \%$ humanities, $14.6 \%$ natural sciences, $10.5 \%$ informatics, $3.7 \%$ sport sciences, $2.1 \%$ social sciences, and $0.6 \%$ economics. Most participants $(73.2 \%)$ were in their first or second year of higher education at the time of the investigation. Of all respondents, $39.6 \%$ were living with their family of origin and $58.1 \%$ were not $(2.3 \%$ of respondents did not indicate their residential status).

All volunteer participants were informed about the aim of the study and provided informed consent to take part in the study. In all, $24.4 \%$ of participants completed the questionnaires in a paper-and-pencil format during a university lecture or seminar, and $75.6 \%$ completed the questionnaires through an online platform. The resulting data were collected in a single database and analyzed together.

\section{Instruments}

\section{Test Anxiety}

Test anxiety was measured using the Cognitive Test Anxiety Scale (CTAS, Cassady \& Johnson, 2002; Hungarian version: Németh \& Bernáth, in press), which is designed to measure cognitive reactions experienced before, during, and after evaluative situations. A scale focused on the cognitive component of test anxiety was chosen because this dimension has been found to particularly diminish academic performance. The cognitive component of test anxiety includes concerns and thoughts revolving around one's own performance, comparisons with others, and consequences of failure, all of which may be particularly relevant when investigating the relationship of family characteristics and self-esteem.

In a previous study that used the Hungarian adaptation of the CTAS (Németh \& Bernáth, in press), the scale comprised three subscales with a total of 20 items measured on a 4-point Likert scale, 6 of which are reversely coded. The general worry (GW) dimension reflects the extent of excitement, worry, or calm experienced by respondents in the context of test situations in general (e.g., While taking a test, I feel confident and relaxed). The freezing up (FU) dimension refers to students being unable to retrieve information from memory or organize their thinking in evaluative situations (e.g., At the beginning of a test, I am so nervous that I often can't think straight). Finally, the fear of failure (FF) dimension contains items that describe students' expectations of poor performance and its negative consequences (e.g., During tests, I find myself thinking of the consequences of failing). The internal consistency values of the subscales were high for the current sample (GW: $\alpha=0.87$; FU: $\alpha=0.88$; FF: $\alpha=0.81$ ).

\section{Global Self-Esteem}

Global self-esteem was measured using the Rosenberg SelfEsteem Scale (Rosenberg, 1965; Hungarian version: Rózsa \& V. Komlósi, 2014), a unidimensional instrument that consists of 10 items ( 5 of which are reversely coded) regarding one's sense of general worthiness of the self, such as On the whole, I am satisfied with myself. Participants indicate to what extent they agree with certain statements on a 4-point Likert-type scale. The Cronbach's alpha value of the scale in this study was 0.91 .

\section{Contingent Self-Esteem}

Contingent self-esteem was measured using the Contingent Self-Esteem Scale (Johnson \& Blom, 2007; Hungarian adaptation: Sági, 2015), which comprises two dimensions: relation-based and competence-based self-esteem. Given the purpose of this study, only the competence-based subscale was used, which consists of 12 statements that describe the extent to which an individual's level of self-esteem depends on competence-related achievements (e.g., It is not 'who I am' but 'what I can accomplish' that matters). The scale does not contain any negatively worded items and has demonstrated appropriate internal consistency $(\alpha=0.83)$.

\section{Family Cohesion}

Family cohesion was measured using the cohesion subscales of the Family Adaptability and Cohesion Evaluation Scale IV (FACES, Olson, 2011; Hungarian adaptation: Mirnics et al., 2010). These subscales include 1 balanced dimension (Family members are supportive of each other during difficult times) and 2 unbalanced dimensions: enmeshed (Family members feel pressured to spend most free time together) and disengaged (Family members are on their own when there is a problem to be solved). Each subscale consists of 7 positively worded items on a 5-point Likert scale, and participants were asked to respond to these items regarding their 
family of origin. The Cronbach's Alpha values were 0.90 for balanced cohesion, 0.80 for disengaged cohesion, and 0.72 for enmeshed cohesion. To manage the influences of all subscales and the curvilinearity of family cohesion, the ratio score of these subscales was used for analysis. According to Olson (2011), the cohesion ratio (which is calculated by dividing the balanced cohesion score by the average of the unbalanced subscales) demonstrates how balanced a family is in terms of cohesion. The higher above 1 the ratio is, the more balanced the family system is.

\section{Data Analysis}

Data collected from 487 subjects were analyzed. Cases with missing data were excluded pairwise in SPSS analyses, and the default full information maximum likelihood (FIML) approach was used in structural equation modeling, which was performed in MPlus. The FIML approach uses all available information for analysis and has proven less biased and more efficient than other techniques of handling missing values (Enders \& Bandalos, 2001). In total, 11.3\% of respondents had missing values; for participants with incomplete datasets, the average proportion of missing data was $6.36 \%$. When investigating missing data regarding certain variables included in the analyses, the proportion of missing values did not exceed $3.5 \%$ for any of the variables $(M=0.71, S D=0.01)$.

Descriptive statistics of the variables examined and independent sample $t$ tests were conducted to compare groups based on gender and residence. These analyses were conducted in SPSS 27. Structural equation modeling (SEM) with maximum likelihood estimation was conducted in MPlus 8 to test the proposed model, which used test anxiety dimensions, global self-esteem, and contingent selfesteem as continuous latent variables and family cohesion as an observed variable. Based on the relatively high number of items and in consideration of the advantages of item parceling (Little et al., 2002), parcels (i.e., aggregated indicators comprised of the average of several individual items) were used as indicators of latent variables instead of the original items. Three parcels with randomly assigned items were used to estimate each construct to avoid underidentified or overidentified latent variables (Little et al., 2002). Latent variables and parcels with corresponding items are presented in Table 1, along with descriptive statistics for each parcel. As mentioned above, the family cohesion ratio was included in the model as an observed variable. A preliminary confirmatory factor analysis was performed to assess the threedimensional structure of FACES, which resulted in acceptable fit indices $(C F I=0.927, T L I=0.915, R M S E A=0.069$, $\left.S R M R=0.066, \chi^{2}=430.870, p<0.001\right)$ after removing three items $(33,34$, and 40$)$. Therefore, a modified version of the instrument that excluded items 33 ("Family members seldom depend on each other"), 34 ("We resent family members doing things outside the family"), and 40 ("Family members feel guilty if they want to spend time away from the family") was used for further analyses. Finally, multigroup analyses were conducted to examine whether the model varied across groups based on gender or residential status.
Table 1 Latent variables and items assigned to certain parcels in the structural model

\begin{tabular}{lllllll}
\hline Scale & Latent variable & Parcel & Items & $n$ & $M$ & $S D$ \\
\hline Cognitive Test Anxiety Scale & General worry & GW1 & $8,16,18$ & 482 & 2.75 & 0.76 \\
& & GW2 & $1,5,17$ & 486 & 2.76 & 0.77 \\
& \multirow{2}{*}{ Freezing up } & GW3 & 9,21 & 482 & 2.94 & 0.72 \\
& & FU1 & $7,14,22$ & 484 & 2.37 & 0.83 \\
& & FU2 & 4,11 & 487 & 2.13 & 0.79 \\
& \multirow{4}{*}{ Fear of failure } & FU3 & 23,27 & 484 & 2.44 & 0.81 \\
& & FF1 & 2,6 & 484 & 2.10 & 0.84 \\
& & FF2 & 19,20 & 487 & 2.21 & 0.83 \\
Rosenberg Self-Esteem Scale & Global self-esteem & FF3 & 12 & 487 & 2.48 & 1.07 \\
& & GSE1 & $1,2,9,10$ & 487 & 2.71 & 0.78 \\
& & GSE2 & $5,6,7$ & 487 & 3.03 & 0.68 \\
Contingent Self-Esteem Scale & Contingent self-esteem & GSE3 & $3,4,8$ & 486 & 3.01 & 0.59 \\
& & CSE1 & $1,7,8,10$ & 485 & 2.49 & 0.59 \\
& & CSE2 & $2,9,11,12$ & 482 & 2.53 & 0.66 \\
& & CSE3 & $3,4,5,6$ & 483 & 2.38 & 0.61 \\
\hline
\end{tabular}

Seven items in the original Cognitive Test Anxiety Scale were removed from the Hungarian version. To avoid confusion, the scale items are numbered in this table according to the original numbering used by Cassady and Johnson (2002)

$G W$ general worry, $F U$ freezing up, $F F$ fear of failure, $G S E$ global self-esteem, $C S E$ contingent self-esteem 


\section{Results}

\section{Descriptive Statistics on the Intended Measures}

The observed means and standard deviations of the main variables are presented in Table 2 for the whole sample and for subgroups based on gender and residence. Independent sample t-tests were run to examine between-group differences. Female participants reported higher test anxiety (GW: $t[469]=-6.43, p<0.001, d=-0.67$; FU: $t$ [474] $=-3.49, p=0.001, d=-0.36$; FF: $t[477]=-2.16$, $p=0.032, d=-0.22)$, contingent self-esteem $(t$ $[470]=-2.76, p=0.006, d=-0.29)$, and adaptive family cohesion $(t[463]=-3.46, p<0.001, d=-0.36)$ than males, whereas male respondents reported higher global self-esteem $(t[479]=2.49, p=0.013, d=0.26)$ than females. There were no significant differences between groups based on residence.

\section{Results of the Structural Model}

Based on theoretical considerations, the structural model included both direct and indirect (mediated by global and contingent self-esteem) paths from family cohesion to test anxiety, and the errors of global and contingent self-esteem were allowed to correlate. The fit indices of the model were found to be appropriate $(C F I=0.965$, $T L I=0.953, R M S E A=0.062, S R M R=0.037, \chi^{2}=252.373$, $p<0.001)$. These results are presented in Fig. 1 .

Global self-esteem was found to negatively predict all test anxiety dimensions (GW: $\beta=-0.285, S . E .=0.067$, $p<0.001$; FU: $\beta=-0.311$, S.E. $=0.065, p<0.001$; FF: $\beta=-0.445$, S.E. $=0.060, p<0.001)$, and contingent self-esteem was found to positively predict all test anxiety dimensions (GW: $\beta=0.310$, S.E. $=0.060, p<0.001$; FU: $\beta=0.236$, S.E. $=0.065, p<0.001$; FF: $\beta=0.322$, $S . E .=0.062, p<0.001)$. Family cohesion was positively associated with global self-esteem $(\beta=0.322$, S.E. $=0.044$, $p<0.001)$ and negatively associated with contingent selfesteem $(\beta=-0.250$, S.E. $=0.047, p<0.001)$. The results revealed no significant associations between family cohesion and test anxiety; however, the indirect paths of cohesion to test anxiety via global and contingent self-esteem were found to be significant. The total, direct, and indirect effects for paths between family cohesion and test anxiety dimensions are displayed in Table 3 . The presence of significant total and indirect effects, as well as nonsignificant direct effects, indicate that the association between family cohesion and test anxiety was fully mediated by global and contingent self-esteem. Wald tests of parameter constraints did not demonstrate significant differences between the

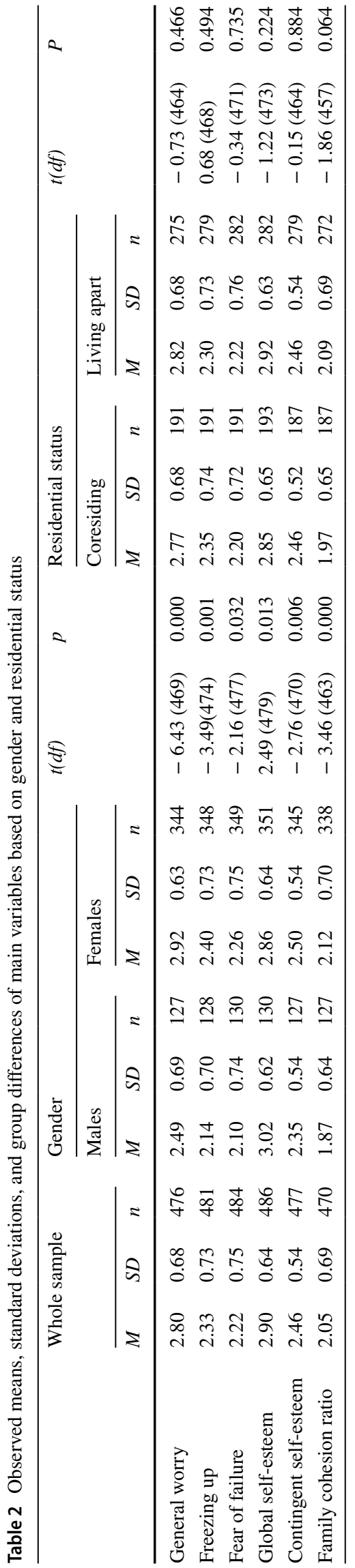




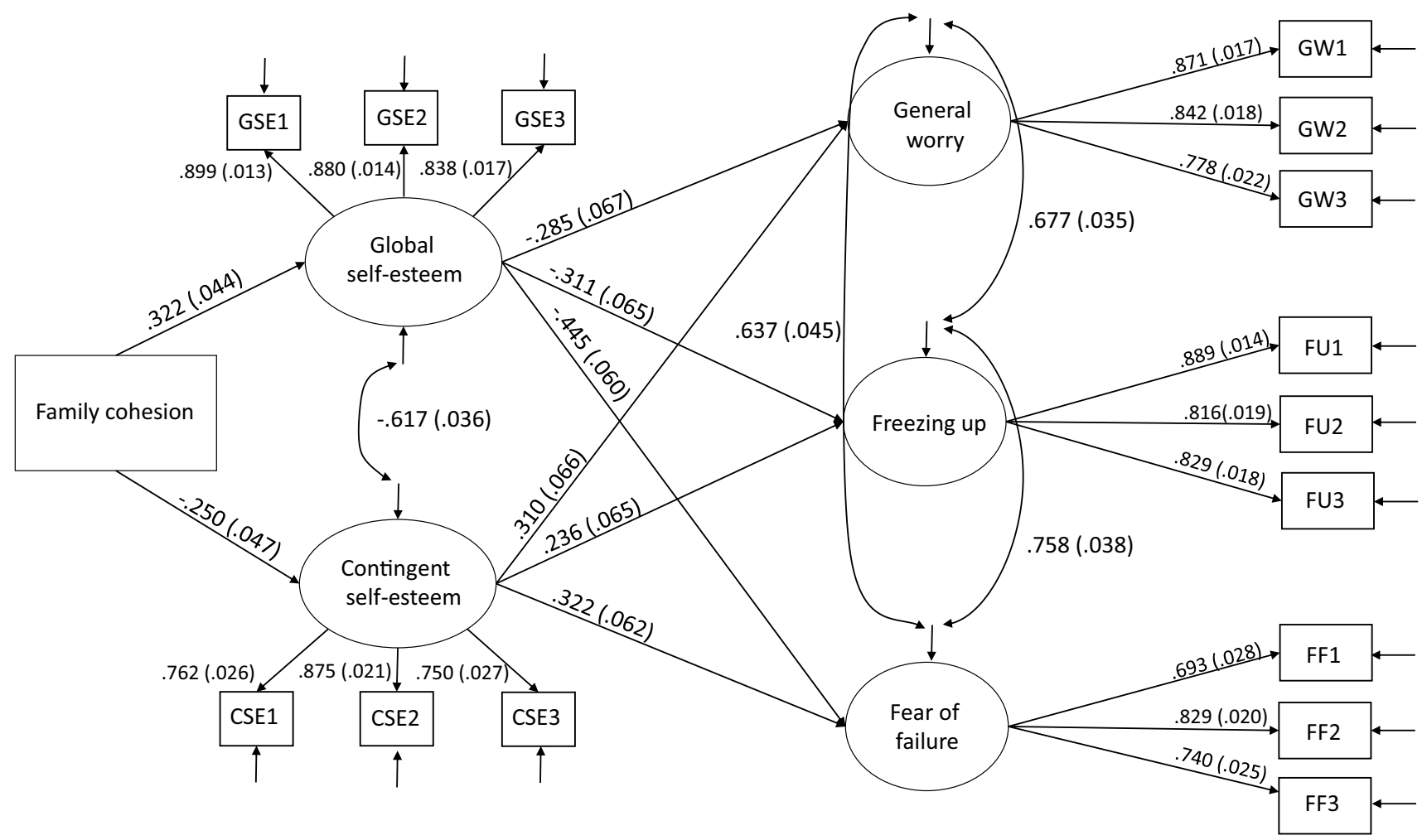

Fig. 1 Structural model of the associations of family cohesion, global and contingent self-esteem, and test anxiety. $N=470$ Standardized beta coefficients and their standard errors (in parentheses) are presented in the figure. For clarity of presentation, nonsignificant direct paths $(p>.05)$ between family cohesion and test anxiety dimensions are not shown. GSE Global self-esteem, CSE Contingent self-esteem, $G W$ General worry, $F U$ Freezing up, $F F$ Fear of failure

Table 3 Total, direct, and indirect effects in the associations between family cohesion and each dimension of test anxiety

\begin{tabular}{|c|c|c|c|c|c|c|c|c|c|}
\hline & \multicolumn{3}{|c|}{ General worry } & \multicolumn{3}{|c|}{ Freezing up } & \multicolumn{3}{|c|}{ Fear of failure } \\
\hline & $\beta$ & $S D$ & $p$ & $\beta$ & $S D$ & $p$ & $\beta$ & $S D$ & $p$ \\
\hline Total effect & -0.109 & 0.049 & 0.025 & -0.233 & 0.046 & 0.000 & -0.228 & 0.049 & 0.000 \\
\hline Direct effect & 0.060 & 0.046 & 0.198 & -0.074 & 0.046 & 0.104 & -0.004 & 0.043 & 0.921 \\
\hline Total indirect effect & -0.169 & 0.028 & 0.000 & -0.159 & 0.026 & 0.000 & -0.224 & 0.033 & 0.000 \\
\hline Indirect effect via global self-esteem & -0.092 & 0.025 & 0.000 & -0.100 & 0.025 & 0.000 & -0.143 & 0.028 & 0.000 \\
\hline Indirect effect via contingent self-esteem & -0.077 & 0.022 & 0.001 & -0.059 & 0.020 & 0.003 & -0.080 & 0.022 & 0.000 \\
\hline
\end{tabular}

strength of the indirect effects of the two mediators $(\mathrm{GW}$ : $\chi^{2}[1]=0.141, p=0.707$; FU: $\chi^{2}[1]=1.232, p=0.271 ; \mathrm{FF}$ : $\left.\chi^{2}[1]=2.799, p=0.094\right)$. The model accounted for $27.5 \%$ of the variance for $\mathrm{GW}, 27.6 \%$ for $\mathrm{FU}$, and $48.9 \%$ for $\mathrm{FF}$ (GW: $R^{2}=0.275$, S.E. $=0.041, p<0.001$; FU: $R^{2}=0.276$, S.E. $=0.040, p<0.001 ; \mathrm{FF}: R^{2}=0.489$, S.E. $=0.044$, $p<0.001)$.

\section{Differences Between Groups Based on Gender and Residence: Multigroup SEM}

The results of the structural model conducted by gender and by residence are presented in Table 4 . Multigroup analyses were conducted to determine whether the model was invariant across groups based on gender and residence. Chi-square difference tests were performed to compare an unconstrained model in which all path coefficients were freely estimated, a fully constrained model in which paths were constrained to be equal across both groups, and partially constrained models in which one path at a time was freely estimated.

In the case of gender, the difference between the fully constrained and unconstrained models was not significant $\left(\Delta \chi^{2}[12]=8.519, p=0.743\right)$, which suggests that the model was similar for men and women. Moreover, investigating certain paths, none of the associations contributed to a significantly better model fit than the fully 
Table 4 Results of the SEM model for groups based on gender and residence: standardized path coefficients, standard errors, and $p$ values

\begin{tabular}{|c|c|c|c|c|c|c|c|c|c|c|c|c|c|}
\hline & \multirow[t]{3}{*}{ Path } & \multirow{2}{*}{\multicolumn{3}{|c|}{$\frac{\text { Gender }}{\text { Males }(n=127)}$}} & & & & \multirow{2}{*}{\multicolumn{3}{|c|}{$\frac{\text { Residential status }}{\text { Coresiding }(n=187)}$}} & & & \\
\hline & & & & & \multicolumn{3}{|c|}{ Females $(n=338)$} & & & & \multicolumn{3}{|c|}{ Living apart $(n=272)$} \\
\hline & & $\beta$ & $S E$ & $p$ & $\beta$ & $S E$ & $p$ & $\beta$ & $S E$ & $p$ & $\beta$ & $S E$ & $p$ \\
\hline 1 & family cohesion global self-esteem & 0.228 & 0.089 & 0.010 & 0.370 & 0.050 & 0.000 & 0.340 & 0.068 & 0.000 & 0.289 & 0.059 & 0.000 \\
\hline 2 & family cohesion contingent self-esteem & -0.134 & 0.096 & 0.163 & -0.311 & 0.054 & 0.000 & -0.235 & 0.077 & 0.002 & -0.215 & 0.063 & 0.001 \\
\hline 3 & global self-esteem general worry & -0.335 & 0.121 & 0.006 & -0.259 & 0.080 & 0.001 & -0.219 & 0.103 & 0.034 & -0.341 & 0.090 & 0.000 \\
\hline 4 & global self-esteem freezing up & -0.353 & 0.115 & 0.002 & -0.280 & 0.078 & 0.000 & -0.296 & 0.101 & 0.003 & -0.341 & 0.087 & 0.000 \\
\hline 5 & global self-esteem fear of failure & -0.467 & 0.108 & 0.000 & -0.425 & 0.072 & 0.000 & -0.406 & 0.096 & 0.000 & -0.537 & 0.079 & 0.000 \\
\hline 6 & contingent self-esteem general worry & 0.242 & 0.126 & 0.054 & 0.290 & 0.079 & 0.000 & 0.367 & 0.100 & 0.000 & 0.253 & 0.091 & 0.006 \\
\hline 7 & contingent self-esteem freezing up & 0.269 & 0.119 & 0.024 & 0.197 & 0.078 & 0.012 & 0.199 & 0.102 & 0.051 & 0.246 & 0.089 & 0.006 \\
\hline 8 & contingent self-esteem fear of failure & 0.293 & 0.113 & 0.010 & 0.326 & 0.073 & 0.000 & 0.394 & 0.095 & 0.000 & 0.211 & 0.084 & 0.012 \\
\hline 9 & family cohesion general worry & -0.049 & 0.085 & 0.563 & 0.024 & 0.058 & 0.679 & 0.068 & 0.074 & 0.358 & 0.023 & 0.060 & 0.697 \\
\hline 10 & family cohesion freezing up & -0.107 & 0.081 & 0.186 & -0.102 & 0.057 & 0.073 & -0.087 & 0.074 & 0.237 & -0.060 & 0.059 & 0.306 \\
\hline 11 & family cohesion fear of failure & 0.055 & 0.078 & 0.485 & -0.035 & 0.054 & 0.514 & 0.046 & 0.071 & 0.514 & -0.019 & 0.056 & 0.731 \\
\hline
\end{tabular}

constrained model. Notably, the link between family cohesion and contingent self-esteem was significant for women $(\beta=-0.311$, S.E. $=0.054, p<0.001)$ but nonsignificant for men $(\beta=-0.134$, S.E. $=0.096, p=0.163)$.

In a comparison of subgroups based on residence, the difference between the fully constrained and unconstrained model was not significant $\left(\Delta \chi^{2}[12]=8.221, p=0.767\right)$. None of the paths contributed to a significantly better model fit when freely estimated.

\section{Discussion}

\section{Overview of Results}

A primary finding of this study is that in addition to global self-esteem being negatively associated with test anxiety, which is aligned with prior research (Dan et al., 2014; Sar1 et al., 2018), contingent self-esteem was also found to be a significant predictor of test anxiety. This result, which confirms the first study hypothesis, is consistent with earlier findings regarding associations between test anxiety and domain-specific contingencies of self-worth (Lawrence \& Smith, 2017; Lawrence \& Williams, 2013). The positive and moderate relationship between contingent self-esteem and test anxiety suggests that students whose self-esteem is based on their competence worry more about examinations than their peers, a finding that is aligned with the selfworth theory of achievement motivation (Covington, 2000) and control-value theory (Pekrun, 2006). The fact that both global and contingent self-esteem predicted test anxiety suggests that low global self-esteem and self-esteem that are highly contingent on external sources should be considered predisposing factors for test anxiety.
Additionally, these results suggest an explanation of the way in which self-esteem affects test anxiety. It could be proposed that individuals with high global self-esteem may be less anxious about tests than their peers because they are convinced of the value of the self; therefore, tests are less threatening for them than for others. However, this hypothesis actually explains the role of contingent self-esteem in test anxiety. An exam may be more anxiety-provoking for a student if their self-esteem is highly dependent on success because, according to the control-value theory (Pekrun, 2006), the perception of serious consequences regarding self-esteem can increase the perceived value of the outcome of an evaluative situation. As for global self-esteem, it is likely that the tendency of students with high self-esteem to think about themselves more positively than their peers do is reflected in their expectations about their skills and the outcomes of upcoming exams. Positive evaluations of oneself may result in feeling able to meet challenges and thereby lower test anxiety. The existing literature regarding the link between self-efficacy and test anxiety supports this assumption (Embse et al., 2018).

The second hypothesis is supported by the SEM results, which demonstrate that the association between family cohesion and test anxiety was fully mediated by self-esteem. This finding highlights the significance of cohesion experienced in one's family of origin during emerging adulthood for test anxiety and contributes to a deeper understanding of the underlying mechanisms of this association. The mediating role of self-esteem may be interpreted as follows: adaptive family cohesion influences test anxiety by increasing global self-esteem and decreasing contingent self-esteem. Families that provide the appropriate extent of emotional closeness and autonomy increase children's level of self-esteem, presumably 
true self-esteem. As a result, these children do not need to gain self-worth through external factors (i.e., contingent self-esteem); therefore, they will be less prone to test anxiety than their peers.

It is notable that the indirect associations between family cohesion and test anxiety were quite weak. It is possible that the family environment plays a crucial role in the development of self-esteem during early socialization (e.g., Kohut, 1971); however, this study only relies on information about the perceived family cohesion of emerging adults. Emerging adults' perceptions of family cohesion tend to be consistent with their judgments at earlier ages (Parra et al., 2015); nevertheless, it is unclear to what extent the present study findings reflect family influence during early development and at the time of the study. Other family factors may also play a role in the development of self-esteem, such as parental conditional regard (Wouters et al., 2018). Nevertheless, the influence of family cohesion on the relationship between self-esteem and test anxiety seems to prevail during emerging adulthood. These results are aligned with earlier findings on the relationship between family cohesion and global self-esteem (Jaggers et al., 2015; White et al., 2014), as well as the importance of family cohesion for the academic and emotional adjustment of emerging adults (Fosco et al., 2012; Givertz \& Segrin, 2014). The present study findings contribute to a deeper understanding of the association between cohesion and test anxiety and add to the existing body of research through the inclusion of mediators and the use of a family cohesion ratio score in analysis, which manages the curvilinearity of cohesion.

The third hypothesis, regarding whether the model differs across gender groups, was partially supported by the study results. The lack of significant differences in the model suggests that the contributions of family cohesion to test anxiety are similar across genders. However, the fact that the link between family cohesion and contingent self-esteem was significant only for female participants suggests that family cohesion may play a more important role in this relationship for women than for men. Gender differences in contingent self-esteem have been identified during adolescence (Schöne et al., 2015); additionally, males and females may differ regarding the contributing factors of contingent selfesteem, although the existing research on this topic is scarce (Wouters et al., 2018). Life events unrelated to the familysuch as romantic relationships (Orth, 2017) or participation in higher education (Hallsten et al., 2012)—can influence the contingency of self-esteem, which develops across the lifespan. A possible explanation for the present study result is that the impact of the family of origin may be overweighed by family-independent influences by the time of emerging adulthood in the case of male participants, whereas the impact of family origin may remain a significant factor for female participants.
The fourth study hypothesis, regarding the moderating role of residential status, was not supported. The influence of family cohesion on intrapersonal outcomes was not stronger for participants who lived with their family of origin. Although participants were asked to indicate their current impressions of their family, it is possible that findings regarding the links between family cohesion, self-esteem, and test anxiety reflect the influence of family relationships during earlier development rather than their current influence. The consequences of family cohesion during earlier development may prevail during emerging adulthood. Longitudinal findings have demonstrated that children's perceptions of family cohesion remain consistent from earlier ages through emerging adulthood (Parra et al., 2015). These findings support the assumption that participants' judgments of cohesion may reveal the characteristics of the environment of their earlier development. Another possible explanation for the lack of difference is that residential status does not necessarily reflect the intensity of family relationships, though it does indicate physical proximity. Emerging adults who live apart from their family of origin can find other ways to stay connected, and the present study design may not account for those alternative relationship avenues.

Finally, it is important to highlight that only $27.5-48.9 \%$ of the variance of test anxiety dimensions was explained by the variables included in the model. This is unsurprising considering that many contributing factors for test anxiety have been identified in previous studies, including schoolrelated variables (e.g., Hoferichter et al., 2014; Liu, 2012), other intrapersonal variables (e.g., Embse et al., 2018; Hembree, 1988), and parental and family variables (e.g., Ringeisen \& Raufelder, 2015; Shadach \& Ganor-Miller, 2013).

\section{Conclusions and Implications}

The present study results demonstrate that family cohesion (an important aspect of family systems and relationships) plays a role in emerging adults' test anxiety (an important aspect of university students' academic and emotional adjustment). The study contributes to a deeper understanding of this association by investigating the mediating roles of global and contingent self-esteem, as well as the influence of two demographic moderator variables, gender and residential status. The family cohesion-test anxiety relationship was fully mediated by both dimensions of self-esteem, in that family cohesion was found to impact test anxiety by enhancing global and lowering contingent self-esteem. These associations were rather weak, and it remains unclear whether these moderating relationships reflect the current influence of the family of origin or its influence during earlier development. The lack of moderating effect of co-residence may 
be considered an argument for the former option; however, further investigation is needed to clarify the potentially moderating role of co-residence and gender in the relationship between family cohesion and contingent self-esteem.

Nevertheless, the influence of the family system seems to prevail during emerging adulthood and should therefore be considered when working with highly test-anxious students. Enhancement of students' self-esteem and mitigation of their urge to earn self-worth through achievements might prove effective aims of interventions to manage test anxiety. The significance of family cohesion and self-esteem points to several factors that could inform student counselors or educators in their efforts to help students. Global self-esteem is an important protective factor that can be supported by giving students authentic and positive feedback on various domains or providing students with opportunities to try different activities. The content and wording of feedback may also be important in consideration of contingent self-esteem: it may be useful to give specific feedback concerning a student's specific performance instead of a general evaluation of the student's skills and abilities. This type of evaluation can enhance a student's growth mindset (rather than fixed mindset), and the perceived significance of a given test for the student's self-esteem may be reduced, resulting in lower test anxiety. Providing multiple opportunities for students to be evaluated course instead of a single high-stakes test may have similar consequences. Although the association of family cohesion may reflect its influence during earlier development, it nevertheless indicates the importance of a warm, supportive social environment surrounding self-esteem and test anxiety, including in peer groups and close friendships. The encouragement of autonomy is another attribute of balanced cohesion that can be provided by educators who practice autonomy-supporting (instead of controlling) behaviors, such as using intrinsic motivators or empowering students to make their own choices.

\section{Limitations and Future Directions}

In addition to its novel findings, this study has several limitations. First, due to the self-reported nature of the data, the results could be affected by factors such as social desirability or common method bias. To confirm measures of self-esteem, it would be useful to repeat the investigation using implicit measures instead of self-reported questionnaires. Additionally, latent classes of individuals could be defined based on global and contingent self-esteem (e.g., combinations of low or high values of both aspects) and compared concerning test anxiety. For this study, the only data available to measure family cohesion were the subjective perceptions of participants. Future research might aim to collect more objective measures of family functioning or discrepancies of the perceptions of family members to determine how these measures are associated with the investigated variables.

In this study, a ratio of scores was used to calculate a measurement on the functional and dysfunctional scales. Further research is needed to investigate whether the present study findings are specific to the family cohesion ratio or would hold for any indicator of family adaptiveness. The meaning of the findings regarding family cohesion could also be further clarified by conducting longitudinal studies, comparing age groups, or considering indicators of the intensity of relationships and family interactions aside from residential status. Based on the present study results and the existing literature, many other factors were beyond the scope of the study but could be investigated in the future. Inclusion of additional family characteristics in the model (e.g., parental attitudes, pressure, or involvement) would help to specify the role of family cohesion, and inclusion of intrapersonal variables (e.g., self-efficacy or perfectionism) would provide information about the different aspects of self-esteem that influence test anxiety.

\section{Data availability and Material}

The data that support the findings of this study are available from the corresponding author upon reasonable request.

Funding Open access funding provided by Eötvös Loránd University. This research did not receive any specific grant from funding agencies in the public, commercial, or not-for-profit sectors.

Code availability Not applicable.

\section{Declarations}

Conflict of interest The authors have no conflict of interest to declare.

Open Access This article is licensed under a Creative Commons Attribution 4.0 International License, which permits use, sharing, adaptation, distribution and reproduction in any medium or format, as long as you give appropriate credit to the original author(s) and the source, provide a link to the Creative Commons licence, and indicate if changes were made. The images or other third party material in this article are included in the article's Creative Commons licence, unless indicated otherwise in a credit line to the material. If material is not included in the article's Creative Commons licence and your intended use is not permitted by statutory regulation or exceeds the permitted use, you will need to obtain permission directly from the copyright holder. To view a copy of this licence, visit http://creativecommons.org/licenses/by/4.0/. 


\section{References}

Abe, J. A. A. (2004). Self-esteem, perception of relationships, and emotional distress: A cross-cultural study. Personal Relationships, 11(2), 231-247. https://doi.org/10.1111/j.1475-6811.2004. 00080.x

Allen, S. F., \& Stoltenberg, C. D. (1995). Psychological separation of older adolescents and young adults from their parents: An investigation of gender differences. Journal of Counselling \& Development, 73(5), 542-546. https://doi.org/10.1002/j.1556-6676.1995. tb01791.x

Arnett, J. J. (2000). Emerging adulthood: A theory of development from the late teens through the twenties. American Psychologist, 55(5), 469-480. https://doi.org/10.1037/0003-066X.55.5.469

Cassady, J. C., \& Johnson, R. E. (2002). Cognitive test anxiety and academic performance. Contemporary Educational Psychology, 27(2), 270-295. https://doi.org/10.1006/ceps.2001.1094

Cerkez, V. C., \& Efendić-Spahić, T. (2016). Perfectionism at younger adolescents: Associations with different aspects of anxiety. Human Research in Rehabilitation, 6(1), 70-80.

Cheung, R. Y. M., Leung, M. C., Chiu, H. T., Kwan, J. L. Y., Yee, L. T. S., \& Hou, W. K. (2019). Family functioning and psychological outcomes in emerging adulthood: Savoring positive experiences as a mediating mechanism. Journal of Social and Personal Relationships, 36(9), 2693-2713. https://doi.org/10.1177/02654 07518798499

Covington, M. V. (2000). Goal theory, motivation, and school achievement: An integrative review. Annual Review of Psychology, 51, 171-200. https://doi.org/10.1146/annurev.psych.51.1.171

Crocker, J., Brook, A. T., Niiya, Y., \& Villacorta, M. (2006). The pursuit of self-esteem: Contingencies of self-worth and self-regulation. Journal of Personality, 74(6), 1749-1772. https://doi.org/10. 1111/j.1467-6494.2006.00427.x

Dan, O., Bar Ilan, O., \& Kurman, J. (2014). Attachment, self-esteem, and test anxiety in adolescence and early adulthood. Educational Psychology, 34(6), 659-673. https://doi.org/10.1080/01443410. 2013.814191

Deci, E. L., \& Ryan, R. M. (1995). Human autonomy, the basis of true self-esteem. In M. H. Kernis (Ed.), Efficacy, agency, and selfesteem (pp. 31-71). Plenum Press.

Embse, N., Jester, D., Roy, D., \& Post, J. (2018). Test anxiety effects, predictors, and correlates: A 30-year meta-analytic review. Journal of Affective Disorders, 227, 483-493. https://doi.org/10. 1016/j.jad.2017.11.048

Enders, C. K., \& Bandalos, D. L. (2001). The relative performance of full information maximum likelihood estimation for missing data in structural equation models. Structural Equation Modeling, 8(3), 430-457. https://doi.org/10.1207/S15328007SEM0803_5

Fosco, G. M., Caruthers, A. S., \& Dishion, T. J. (2012). A six-year predictive test of adolescent family relationship quality and effortful control pathways to emerging adult social and emotional health. Journal of Family Psychology, 26(4), 565-575. https://doi.org/ $10.1037 / \mathrm{a} 0028873$

Ginsburg, G. S., Silverman, W. K., \& Kurtines, W. K. (1995). Family involvement in treating children with phobic and anxiety disorders: A look ahead. Clinical Psychology Review, 15(5), 457-473. https://doi.org/10.1016/0272-7358(95)00026-L

Givertz, M., \& Segrin, C. (2014). The association between overinvolved parenting and young adults' self-efficacy, psychological entitlement, and family communication. Communication Research, 41(8), 1111-1136. https://doi.org/10.1177/0093650212 456392

Gorbett, K., \& Kruczek, T. (2008). Family factors predicting social self-esteem in young adults. The Family Journal, 16(1), 58-65. https://doi.org/10.1177/1066480707309603
Guassi Moreira, J. F., \& Telzer, E. H. (2015). Changes in family cohesion and links to depression during the college transition. Journal of Adolescence, 43, 72-82. https://doi.org/10.1016/j.adolescence. 2015.05.012

Hallsten, L., Rudman, A., \& Gustavsson, P. (2012). Does contingent self-esteem increase during higher education? Self and Identity, 11(2), 223-236. https://doi.org/10.1080/15298868.2010.544872

Hembree, R. (1988). Correlates, causes, effects, and treatment of test anxiety. Review of Educational Research, 58(1), 47-77. https:// doi.org/10.3102/00346543058001047

Hoferichter, F., Raufelder, D., \& Eid, M. (2014). The mediating role of socio-motivational relationships in the interplay of perceived stress, neuroticism, and test anxiety among adolescent students. Psychology in the Schools, 51(7), 736-752. https://doi.org/10. 1002/pits.21778

Hong, R. Y., Tan, C. S., Lee, S. S. M., Tan, S.-H., Tsai, F.-F., Poh, X.-T., Zhou, Y., Sum, E. L., \& Zhou, Y. (2015). Interactive effects of parental personality and child temperament with parenting and family cohesion. Parenting, 15(2), 92-118. https:// doi.org/10.1080/15295192.2015.1020143

Jaggers, J. W., Church, W. T., II., Tomek, S., Hooper, L. M., Bolland, K. A., \& Bolland, J. M. (2015). Adolescent development as a determinant of family cohesion: A longitudinal analysis of adolescents in the Mobile Youth Survey. Journal of Child and Family Studies, 24(6), 1625-1637. https://doi.org/10.1007/ s10826-014-9966-8

Johnson, M., \& Blom, V. (2007). Development and validation of two measures of contingent self-esteem. Individual Differences Research, 5(4), 300-328.

Kins, E., Beyers, W., Soenens, B., \& Vansteenkiste, M. (2009). Patterns of home leaving and subjective well-being in emerging adulthood: The role of motivational processes and parental autonomy support. Developmental Psychology, 45(5), 14161429. https://doi.org/10.1037/a0015580

Kohut, H. (1971). The analysis of the self. International Universities Press.

Lawrence, J. S., \& Smith, J. L. (2017). Academically contingent selfworth and vulnerability: When approach self-validation goals are more threatening than avoidance self-validation goals. Self and Identity, 16(3), 353-372. https://doi.org/10.1080/15298868. 2017.1292183

Lawrence, J. S., \& Williams, A. (2013). Anxiety explains why people with domain-contingent self-worth underperform on ability-diagnostic tests. Journal of Research in Personality, 47(3), 227-232. https://doi.org/10.1016/j.jrp.2013.01.004

Little, T. D., Cunningham, W. A., Shahar, G., \& Widaman, K. F. (2002). To parcel or not to parcel: Exploring the question, weighing the merits. Structural Equation Modeling, 9(2), 151173. https://doi.org/10.1207/S15328007SEM0902_1

Liu, Y. Y. (2012). Students' perception of school climate and trait test anxiety. Psychological Reports, 111(3), 761-764. https:// doi.org/10.2466/11.10.21.PR0.111.6.761-764

Lopez, F. G., Campbell, V. L., \& Watkins, C. E. (1988). Family structure, psychological separation, and college adjustment: A canonical analysis and cross-validation. Journal of Counseling Psychology, 35(4), 402-409. https://doi.org/10.1037/00220167.35.4.402

Mazurik, K., Knudson, S., \& Tanaka, Y. (2020). Stuck in the nest? A review of the literature on coresidence in Canada and the united states. Marriage \& Family Review, 56(5), 491-512. https://doi. org/10.1080/01494929.2020.1728005

McDonald, A. S. (2001). The prevalence and effects of test anxiety in school children. Educational Psychology, 21(1), 89-101. https:// doi.org/10.1080/01443410020019867 
Mirnics, Zs., Vargha, A., Tóth, M., \& Bagdy, E. (2010). Cross-cultural Applicability of FACES IV. Journal of Family Psychotherapy, 21(1), 17-33. https://doi.org/10.1080/08975351003618577

Naveh-Benjamin, M., Lavi, H., McKeachie, W. J., \& Lin, Y. (1997). Individual differences in students' retention of knowledge and conceptual structures learned in university and high school courses: The case of test anxiety. Applied Cognitive Psychology, 11(6), 507-526. https://doi.org/10.1002/(SICI)1099-0720(199712)11:6\% 3c507::AID-ACP482\%3e3.0.CO;2-G

Neff, K. D., \& McGehee, P. (2010). Self-compassion and psychological resilience among adolescents and young adults. Self and Identity, 9(3), 225-240. https://doi.org/10.1080/15298860902979307

Németh, L., \& Bernáth, L. (in press). The nature of cognitive test anxiety: An investigation of the factor structure of the cognitive test anxiety scale. Educational Assessment.

Newman, K. S. (2013). The accordion family boomerang kids, anxious parents, and the private toll of global competition. Beacon Press.

Olson, D. H. (2011). FACES IV and the circumplex model: Validation study. Journal of Marital and Family Therapy, 37(1), 64-80. https://doi.org/10.1111/j.1752-0606.2009.00175.x

Olson, D. H., Sprenkle, D. H., \& Russell, C. S. (1979). Circumplex model of marital and family systems: I Cohesion and adaptability dimensions, family types, and clinical applications. Family Process, 18(1), 3-28.

Orth, U. (2017). The lifespan development of self-esteem. In J. Specht (Ed.), Personality development across the lifespan (pp. 181-195). Elsevier Academic Press. https://doi.org/10.1016/B978-0-12804674-6.00012-0

Parra, A., Oliva, A., \& del Carmen Reina, M. (2015). Family relationships from adolescence to emerging adulthood: A longitudinal study. Journal of Family Issues, 36(14), 2002-2020. https://doi. org/10.1177/0192513X13507570

Pekrun, R. (2006). The control-value theory of achievement emotions: Assumptions, corollaries, and implications for educational research and practice. Educational Psychology Review, 18, 315341. https://doi.org/10.1007/s10648-006-9029-9

Peleg, O. (2002). Children's test anxiety and family interaction patterns. Anxiety Stress and Coping, 15(1), 45-59. https://doi.org/ $10.1080 / 10615800290007281$

Peleg, O. (2004). Differentiation and test anxiety in adolescents. Journal of Adolescence, 27(6), 645-662. https://doi.org/10.1016/j. adolescence.2004.06.002

Peleg, O., \& Klingman, A. (2002). Family environment, discrepancies between perceived actual and desirable environment, and children's test and trait anxiety. British Journal of Guidance \& Counselling, 30(4), 451-466. https://doi.org/10.1080/0306988021 000025646

Peleg, O., \& Zoabi, M. (2014). Social anxiety and differentiation of self: A comparison of Jewish and Arab college students. Personality and Individual Differences, 68, 221-228. https://doi.org/10. 1016/j.paid.2014.04.032

Ringeisen, T., \& Raufelder, D. (2015). The interplay of parental support, parental pressure, and test anxiety - Gender differences in adolescents. Journal of Adolescence, 45, 67-79. https://doi.org/ 10.1016/j.adolescence.2015.08.018
Rosenberg, M. (1965). Society and the adolescent self-image. Princeton University Press. https://doi.org/10.1126/science.148.3671. 804

Rózsa, S., Komlósi, V., \& A. (2014). Rosenberg Önbecsülés Skála pszichometriai jellemzői: A pozitívan és negatívan megfogalmazott tételek múködésének sajátosságai [Psychometric properties of the Rosenberg self-esteem scale: Functioning of positively and negatively worded items]. Pszichológia, 34(2), 149-174. https:// doi.org/10.1556/Pszicho.34.2014.2.4

Sági, A. (2015). A feltételes önbecsülés skála (CES-H) magyar változatának validálása és pszichometriai jellemzői [Validation and psychometric properties of the Hungarian version of the contingent self-esteem scale]. Magyar Pszichológiai Szemle, 70(4), 787-805. https://doi.org/10.1556/0016.2015.70.4.5

Sarı, S. A., Bilek, G., \& Çelik, E. (2018). Test anxiety and self-esteem in senior high school students: A cross-sectional study. Nordic Journal of Psychiatry, 72(2), 84-88. https://doi.org/10.1080/ 08039488,pp.1389986,2017

Schöne, C., Tandler, S. S., \& Stiensmeier-Pelster, J. (2015). Contingent self-esteem and vulnerability to depression: Academic contingent self-esteem predicts depressive symptoms in students. Frontiers in Psychology, 20(6), 1573. https://doi.org/10.3389/fpsyg.2015. 01573

Segrin, C., Kauer, T. B., \& Burke, T. J. (2019). Indirect effects of family cohesion on emerging adult perfectionism through anxious rearing and social expectations. Journal of Child and Family Studies, 28, 2280-2285. https://doi.org/10.1007/s10826-019-01444-2

Shadach, E., \& Ganor-Miller, O. (2013). The role of perceived parental over-involvement in student test anxiety. European Journal of Psychology of Education, 28(2), 585-596. https://doi.org/10. 1007/s10212-012-0131-8

Ward, R. A., \& Spitze, G. D. (2007). Nestleaving and coresidence by young adult children: The role of family relations. Research on Aging, 29(3), 257-277. https://doi.org/10.1177/0164027506 298225

White, J., Shelton, K. H., \& Elgar, F. J. (2014). Prospective associations between the family environment, family cohesion, and psychiatric symptoms among adolescent girls. Child Psychiatry and Human Development, 45(5), 544-554. https://doi.org/10.1007/ s10578-013-0423-5

White, L. K., \& Rogers, S. J. (1997). Strong support but uneasy relationships: Coresidence and adult children's relationships with their parents. Journal of Marriage and the Family, 59(1), 62-76. https://doi.org/10.2307/353662

Wouters, S., Colpin, H., Luyckx, K., \& Verschueren, K. (2018). Explaining the relationship between parenting and internalizing symptoms: The role of self-esteem level and contingency. Journal of Child and Family Studies, 27(10), 3402-3412. https://doi.org/ 10.1007/s10826-018-1167-4

Publisher's Note Springer Nature remains neutral with regard to jurisdictional claims in published maps and institutional affiliations. 